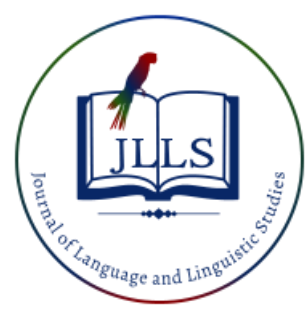

Available online at www.jlls.org

JOURNAL OF LANGUAGE

AND LINGUISTIC STUDIES

ISSN: 1305-578X

Journal of Language and Linguistic Studies, 17(4), 1787-1805; 2021

\title{
A video-book translation project for deaf children
}

\author{
Ayşe Şirin Okyayuz a ${ }^{1}$ iD \\ ${ }^{a}$ Hacettepe University, Department of Translation and Interpreting in Ankara, Turkey
}

\section{APA Citation:}

Okyayuz, A.S. (2021). A video-book translation project for deaf children. Journal of Language and Linguistic Studies, 17(4), 1787-1805. Doi: $10.52462 / \mathrm{jlls} .130$

Submission Date:03./03/2021

Acceptance Date:14/06/2021

\begin{abstract}
In the 21st century, providing accessibility for all to all products and platforms including cultural and literary products is one of the most important fields of study embraced in translation and interpreting studies, media accessibility studies and others. With governments and international organs like the UN and EU working towards full accessibility, it falls to multidisciplinary teams to produce accessible versions of such products and furthermore to provide road maps, guidelines and examples of good practice. The following article outlines a project undertaken with these priorities and concerns. In response to requests from parents with $\mathrm{D} / \mathrm{deaf}$ children and the wishes of the author N. Neydim, work began on the translation and the intermedial adaptation of the Turkish children's books series Selim'in Maceraları (2011) in May of 2019. The project was completed and the video-books are currently available online. The initial aims of the project were, to raise awareness about children's literature in Turkish among preschool and early primary school age Deaf children and to provide these children with the Turkish sign language video-book versions of the author's works. The following article details the design and implementation of the project, the project cycle, profiles of the interpreting team, technical and design concerns, and options and decisions about the interpreting process to provide an example for similar endeavours and a platform for sharing insight on the issues inherent to the project.
\end{abstract}

Keywords: Deaf children; children's books in Turkish; Turkish sign language; translation of children's books; translation projects

\section{Introduction}

In the 21st century with initiatives like the UN Convention on the Rights of Persons with Disabilities (CRPD 2006) efforts to provide accessibility grow. According to the guiding principles of the CRPD, accessibility, full and effective participation and inclusion in society, respect for the evolving capacities of children with disabilities, and respect for the rights of children with disabilities to preserve their identities are essential.

To provide access to material and products for all, especially for the blind, D/deaf and Hard of Hearing $(\mathrm{HoH})$, in the last two decades, researchers in communication and media studies (for example see: Ellis \& Kent, 2011; Lazar \& Stein, 2017), and those working on the intersection between translation studies and MA studies (for example see: UMAQ- Understanding Media Accessibility

\footnotetext{
1 Corresponding author:

E-mail address: sirinokyayuz@hacettepe.edu.tr
} 
Quality, 2017; Media for All-M4A8, 2019) have drafted guidelines and standards and conducted research on new technologies.

In the case of Deaf children who use a sign language as mother tongue (L1), accessibility to many products and services is provided through sign language interpreting. Though such efforts continue to flourish and multiply, there tends to be less scholarly work on the specifics of translating/interpreting in the context of literature for D/deaf children. This fact becomes apparent when the number of works on more traditional and widespread practices such as the study of interlingual translation of children's literature in other languages is compared with the subject matter in question.

Today, thanks to interlingual translation, the children's bookshelf comprises books from various cultural horizons (Mdallel, 2003, pp.298-299; Heilbron, 1999, p.432). A comprehensive example of this wide dissemination is provided in the translated children's book catalogue by Hallford and Zaghini (2005). Translation of children's literature is studied extensively within contemporary translation studies.

This area of study has witnessed a significant growth in scholarly interest in the 21st century (Van Collie \& Verschueren, 2006, p.vi). Seminal work by Shavit (1996), Oittinen (2000), volumes by Lathey $(2006 ; 2010)$ and other works also attest to this fact (also see: O'Connel, 2006, pp.14-25; Pinsent, 2006). The translations of different types and genres of literature across a wide range of language combinations have been studied; but there are relatively few studies concentrating on literature and Deaf children. There is extensive research on reading books with Deaf children (e.g. Swanwick \& Watson, 2007; Berke, 2013; Wauters \& Dirks, 2017) or interactive reading with Deaf children (e.g., Trussel \& Easterbrooks, 2013; Arfé et al, 2015; Calderon, 2000) or the reading related cognitive abilities of Deaf children (e.g., Rhys-Jones \& Ellis, 2000; Messier \& Wood, 2015; Jackson, 2001); but there is relatively little research and (more importantly for those countries and languages that do not have experience in the endeavour) descriptive studies concerning sign language interpreting of literary books for Deaf children.

There are various examples available online (for examples available online on YouTube:https://www.youtube.com/playlist?list=PLhR7lag5IHU9xslintb83KYQMtq33SfH0; for examples for home-schooling see: https://homeschoolmasteryacademy.com/signlanguage-books-kids/; for examples of compilations see: http://1001booksinasl.blogspot.com/). Though examples of sign language interpreting of literature for Deaf children exist (for examples of projects with explanations see: Texas Deaf and Hard of Hearing Services, 2018), these are studied or described relatively less extensively. Furthermore, these have been rarely studied from the perspective of diverse actors (e.g., receivers, translation studies scholars, Deaf studies scholars) or from a multi-faceted perspective to improve practice and quality. The sign language interpreting of a children's book is a process that entails many decisions and if a certain quality is to be targeted a well thought out project. As was the experience in Turkey and probably other countries where such practices are not currently widespread or where there is no previous experience there is currently almost no literature detailing the process and actors which could serve as a starting point for those new to the endeavour.

One could argue that written language (published children's books) may be commonly accessed by both the Deaf and other child readers, and thus need not be translated into sign language. On the other hand, a Deaf child's reality and linguistic skill development will differ from that of other children (for research see Hoffmeister et al, 2000; Baker et al 2016- pp. Chapter 4). As will be described and explained in later sections, the project to be presented here and others like it are essential for their linguistic, cultural and social development. Furthermore, such endeavours differ from other types of translation projects and products studied within translation of children's literature in translation studies. For example, in the case of sign language interpreting of printed children's books for Deaf 
children there are two major 'shifts' from the original text. Initially there is a transfer from a source language into a target language. In addition, there is a shift from a written language to a non-written language. This occurs as written texts are replaced with signed videos. Thus, there is a form of intermedial (from the written medium to signed medium/format) or if one should prefer the notion intersemiotic (from a written sign system to non-written, signed system) or even intermodal (between two modes of language -written and signed) translation involved (for detailed discussion of multimodality and translation see Gambier, 2006; Taylor, 2013, 2016). This type of an endeavour is rarely discussed in the literature children's books translations. On the other hand, such initiatives are imperative in the new order embracing accessibility for all. Furthermore, such initiatives are complex requiring extensive planning in terms of design and implementation. The design of such projects also affects the translation process and product. For example, decisions about design (e.g., the positioning of the interpreter on the screen to point to illustrations) also affect the details of the interpreting process. Thus, crucial issues such as the project team composition, the process involved and the decisions to be made all require careful planning. This article aims to contribute to this field of research in providing an example of a project that was designed to not only provide the type of translated material referred to, but also to research the possibilities in practice to provide food for thought for other similar projects.

\section{Designing and implementing a video-book translation project for Deaf children}

In response to requests from parents with D/deaf children within the Deaf community and the wishes of author N. Neydim, work began on the translation (from written Turkish to Turkish sign language -TID) and intermedial adaptation (from print to video) of the Turkish children's books series Selim 'in Maceraları 1, 2, 3 (2011a, 2011b, 2011c) [Selim's Adventures] in May 2019. The project was completed and presented online (see: http://sebeder.org/film-arsivi.php) in September 2019. The team consisted of several parties: Two non-governmental organizations, SEBEDER [Association for Audio Description] (SEBEDER, 2019) and Türkiye İşitme Engelliler Derneği [Turkish HearingImpaired Association] (TIED, 2019), three academics and children's books translators from translation and interpreting departments in Turkey (Hacettepe University, Bilkent University, İstanbul University), an expert on children's literature, a Deaf editor, a Deaf interpreter, a CODA (children of Deaf adult) interpreter (with TID-Turkish language combination) project supervisor and technical staff.

The initial aim of the project was to raise awareness about children's literature in Turkish among preschool and early primary school age Deaf children. It was noted that literacy and schooling rates (i.e., the rate of Deaf children attending school) were low among the Community (see state-initiated research on statistics in TUIK \& ASPB, 2010). There were several sub-aims: a) developing Deaf children's interest in literary works; b) contributing to their socialization skills and skills to coexist within the larger community; c) augmenting their literary and aesthetic development; d) presenting them with accessible versions of books in their L1 of which they have a wider command then any form of Turkish (written or spoken); e) drafting a project guideline which would map out 'good practices' and options in similar projects; and f) raising awareness among authors, publishers, NGOs and the D/deaf about such endeavours.

\subsection{The project cycles: Aims, participants and workflow}

The project consisted of six consecutive work cycles. In the first cycle the project team held a daylong meeting during which they mapped out the aims, the work and time plan, the resources to be consulted, and the research to be undertaken. The author of the literary texts consulted with his 
publishing house and illustrator to ensure that there were no legal impediments to producing accessible versions of his work. After obtaining written consent, the author gave the project team the illustrations in electronic format.

In the second cycle, the Deaf editor's, interpreter's and project supervisor's, author's and translation studies scholars' roles were defined along with guidelines about decision making during the project. It was decided that all decisions regarding interpreting and design would be taken as a group. Even though the author would be consulted in all instances, the final decision as regards the details of the accessible version (e.g., word choices, deletions, additions) would be made by the members of the group who used TID as L1 and regularly interacted with the target receivers (Deaf children).

The third cycle was the recording of a pilot version of a section of one of the books. The interpreting team (the Deaf editor, Deaf interpreter and CODA supervisor) went through the printed material, discussed difficulties and provided a written version of their draft in TID. The written draft was essentially a gloss (the written transcript of the sign language version) that included not only the signed words (written in UPPERCASE in the example given below) but also various notations (written in lowercase in the example given below) to account for the facial and body grammar that goes with the signs (e.g., "MY NAME SELIM. MY SURNAME CAN. CONFUSE ME -negation- WITH OTHER"). This transcription allowed the translation scholars and the author to map out the translation shifts (i.e., departures from formal correspondence in the process of going from the source language to the target language) in the texts and to designate where systematic decisions were required. For example, decisions regarding use of finger spelling for character names in TID or designating sign language names (signs) for each character were taken at this stage. This pilot run allowed the project team to understand the essence of interpreting for children from Turkish into TiD. It also allowed the project team to make systematic interpreting choices suited to the realities of the age group and culture of the child receivers. The translator-scholars presented possible strategies to be used in interpreting (e.g. the explicitation and free translation of the lyrics of a common children's song cited in the story by deleting repetitions used to synchronize the lyrics with the rhythm and duration of the music), the children's literature expert edited and replaced words, phrases, notions and ideas to make the material relatively more accessible and contributed to forming an easy to-access version, and the author ensured that the work in question reflected the story lines of his books.

The fourth cycle was the actual recording and editing of the material. The final drafts were viewed and discussed by the team and handed over to SEBEDER for technical editing. Decisions regarding presentation and design that are presented in section 4 were discussed in this cycle.

In the fifth cycle the project team drafted the project manual. Each step of the project, the roles of the team members, the profiles of possible contributors, the decisions to be taken and options available, the possible outcomes of each decision, possible translation problems encountered in such an endeavour and other issues were noted by the group. References to previous work and literature in the relevant fields (i.e., reception of children's literature, working with Deaf children, intermedial translation/adaptation) were also included in a references section to ensure that readers of the manual understood the reasoning behind each decision made. The aim was not to provide a definitive guideline, but to provide a reference in which multiple options (e.g., about work processes, design, interpreting choices) were presented for similar projects.

In the sixth cycle the videos were uploaded to a designated site; the lessons learned were added to the manual. 


\subsection{Profiles of the interpreting team}

In a multidisciplinary project with academics and practitioners from various fields (e.g., children's literature, translation, sign language interpreting, design) it is imperative to map out the professional profiles and roles of the team members and recruit accordingly from the start. The profiles and roles of the academics or author are probably clear and do not need to be explained. However, since in countries like Turkey where there is no undergraduate level training in either sign language or sign language interpreting the interpreting team need to be recruited from among self-proclaimed practitioners. Thus, the profiles and roles of these team members need to be considered carefully. Ultimately the final product will be the work of these experts. The following profiles reflect the descriptions of both the roles and the qualifications of the project team members used in the project.

\subsubsection{Deaf Editor}

The editor should have TID as L1 and the ability to conduct group work. The editor should also be able understand the differences between editing a project and interpreting a project. Editors need not interfere in all choices made by the interpreter and should be able to differentiate between interpreter choices that are personal choices and interpreter choices that impact the quality of the interpreting. There is a so-called desired level of interference regarding interpreters' choices. For example, the editor may not need to interfere if the interpreter chooses the sign name 'Curly Head' for a character even if the editor would have preferred 'Red Head'. But s/he will need to interfere if the interpreter opts to fingerspell all names instead of assigning signed names as this will impact the quality of the interpreting (see section 3.1 on interpreting character names for details). S/he should have experience working with Deaf children (e.g., in education, in NGOs) and previous professional or otherwise provable experience of interaction with Deaf children. Furthermore, an interest in written children's literature in Turkish, the ability to comprehend written Turkish, the ability to grasp the intricacies of the literary work in question and a command of narrative techniques of fictional storytelling in the Deaf children's culture are also important.

\subsubsection{Deaf Interpreter}

The Deaf interpreter should have TID as L1 and preferably experience in interpreting (for example, interpreting between TID and another sign language). In the Turkish setting as has been noted in previous experiences, it is extremely hard to explain the interpreter's roles, choices and the details of choices to be made in the process of interpreting to a non-interpreter. For example, in a previous project where a Deaf individual who had experience in storytelling but no experience in interlingual interpreting was considered, the editor and the supervisor had to initially explain simple notions ('do not summarize the text, do not add information to the text unless it is to explain something, do not try to interpret every word in the written text express it naturally in L1' etc.). They also had to explain the act of interpreting starting from the basics. A Deaf interpreter working between two sign languages would have the necessary experience and would not need to be trained at length by the project team. This professional should be able to work in a group and have experience working with Deaf childrenas was the case for the Deaf editor. Furthermore, it is important for the interpreter to be able to use their sign language in a way that is appealing to child audiences (i.e., flowing use of signs, a warm expression, no didactic statements- this is like the 'tone' of the reader in children's audiobooks). S/he should be able to use gestures and mimics in line with the intended emotions and expressions keeping the intended receiver profile in mind. The interpreter needs to have a good grasp of the use of sign language among the intended age group and a command of the level of their vocabulary. In cases where this is possible, the interpreter should have previous training or experience in using their sign language with children. The interpreter also needs to be able to mentally visualise and 'live' the story as an active participant in the storytelling. This is important to ensure that the image of the interpreter 
added to the static illustrations provides a visual story and that the storytelling is not devoid of movement. (N.B. In the video the interpreter will be active whereas the illustrations will be static). The ability to role shift is also important. Role shifting is an indexing part of the grammatical structure of sign languages. It indicates who says and/or what a character does. This grammatical device is commonly used in dialogues or narrative between two characters or persons. The signer moves his/her body, head, and/or eyes to assume the role of the person or character. S/he also takes on other affective or characteristic traits of the role or character (for details see Quer, 2018). Thus, it is also important for the interpreter to be able to physically project or mimic the image of different characters (e.g., parents, child, grandparents), thus lending a different 'discourse' (like a 'voice' in spoken language). The same is also true of animal characters (e.g., angry cat, spooky owl). The interpreter should abide by standard dress codes for sign language interpreting (e.g., dressing in colours that contrast with hands).

\subsubsection{Interpreting Team Supervisor}

The interpreting team supervisor should be a person with an excellent command of both written and spoken Turkish and TID. A CODA, -Child of Deaf Adult- persons who have one or more parent with a demonstrable and verifiable hearing loss- may be preferred. These individuals are usually bicultural and bilingual (for detailed explanation see Mudgett de Caro, 2011). Experience working with Deaf children is also necessary. The expert should be able to work in a group and understand the responsibilities that fall to a supervisor (i.e., not a passive actor overseeing the process but intervening in instances where aims are not met). This person should have, experience in interpreting audio-visual material for Deaf children. The ability to analyse visual and written language both separately (in terms of individual features) and in an integrated manner are also important. Furthermore, the supervisor must have the ability to transcribe TID into written Turkish and take notes of important decisions to be presented to the academic staff for the drafting of the manual.

\subsubsection{Deaf Child}

The final member of the interpreting team would be a Deaf child receiver (with TID as L1) of the age group targeted in the project. This child would need to have the patience to sit through the recordings. Furthermore s/he must have an interest in stories and storytelling and the ability to empathize with characters and the storyline. The Deaf child must also possess the self-confidence to express their views when they have not understood the interpreting. It is crucial to obtain written permission from the parents of the child. Such a member must also be accompanied by an adult throughout the project. The project needs to proceed at a pace at which the team member could follow and not become over-fatigued.

\section{The Interpreting Process}

It would be impossible to provide a comprehensive list of the options available to the team during the interpreting process or the range of decisions to be made. The following section groups together and presents some issues to be considered as well as options regarding problems encountered during the interpreting process.

\subsection{Interpreting character names}

The Turkish Deaf Community uses fingerspelling to spell out their names or names of people, characters etc. that they encounter for the first time. After some time and if the person is frequently referred to, a sign name will be given to that person (for explanation see: Mindess, 1990; Paales, 2011). In a storybook for Deaf children, it is essential that characters are given a sign name as they are introduced, to ensure that the story is appropriate for the culture of the Deaf child (for the options of 
adapting names in children's books translation see: Fernandez, 2006; Puurtinen, 1995, p.22; Rosenheim, 1967; Yamazaki, 2002). Since sign names may be given based on physical features of an individual, for example, in the Selim series the main character Selim was given the sign name - DİK SAÇLI (spiky head) as he styles his hair in this manner. Selim was illustrated with spiked hair throughout the series.

Characters surrounding Selim were given names according to their relation to Selim (unless otherwise necessary) such as SELIM ANNE (Mother Selim). Other important recurring characters in the story were also given sign names (e.g., Curly head). The decision to give a sign name to a character depends on the importance, frequency of appearance and reference to the said character in the story. Creating a sign name can be difficult when the character in question does not have a highly distinctive physical feature on which to base the name. For example, though one of Selim's girlfriends in the story was a central character, the interpreting team was unable to find a sign name that would suit the character and appeal to Deaf children. They chose to refer to her using her relation to Selim (e.g., Selim girlfriend).

\subsection{Interpreting story titles}

Adaptations of book titles to suit the target culture and to adequately present the product are topics frequently treated in translation studies (for discussion see Jovanovich, 1990; Viezzi as quoted in Darwish \& Sayaheen, 2019). Though there are many possible approaches, it may be broadly posited that a) the title should appeal to Deaf child readers, b) should be representative of the story of the book, c) should as far as possible coincide with the original title. Some translation techniques were discussed and used to ensure the titles would be appealing in TID. The first was using clear, expressive and short titles (e.g., 'Selim, Salata Yapan Çocuk' - 'Selim, the Kid Who Makes Salad' was shortened to SELIM SALATA YAPMAK (Selim Salad Make). The project team also did not use non-defining relative causes in titles (e.g., the non-defining relative clause 'who catches' has been deleted in the following

- 'Ali: Yıldızları Yakalayan Çocuk- Ali: The Child Who Catches Stars' versus ALİ YILDIZLARI YAKALAMAK- (Ali Stars Catch)). Words that express the central theme of the story but that may not have been understood by the Deaf child reader were explained (e.g., the fact that daisy is a type of flower was explained- 'Papatya Dostum Benim- My Daisy Friend'vs. BENIM DOST PAPATYA ÇİÇEK- (My

friend the flower Daisy)). Titles were adapted when there were direct references to the hearing culture (e.g., 'speaking the same language' is replaced with 'communicating'- Aynı Dili KonuşmakSpeaking the Same Language vs. INSANLAR, HAYVANLAR İLETIŞiM KURMAK- People, Animals Communicate).

\subsection{Adaptation to the target receivers}

It is always important to 'know your readers' when translating children's books. Reading skills are vital to the enjoyment of literature as research in the United Kingdom has shown (Department of Education, 2012). During the project, the team had to take into consideration that both the cultural background and the native languages of the receivers of the original book and the interpreted videos were different (children reading Turkish with Turkish L1 vs. Deaf children with TID L1). They were children of the same age and were growing up in the same social environment. However, it was important to consider that though they may physically develop at the same speed, Deaf children will not have the same level of wider social development because of not being able to communicate with the dominant (spoken) language of the community (Calderon \& Greenberg, 2012). Whereas the 
hearing child interacts with the hearing world surrounding them as soon as they can communicate, such is not the case for the Deaf child.

The text that was interpreted was a written text. Hearing children learn to read at school (i.e., when they are at least 5-6 years old). Thus, a hearing child can only enjoy the author's work at a younger age if it is read to him/her or when they learn to read. But the Deaf child learns sign language at an earlier age. Since the text is interpreted into TID a younger Deaf child may also be able to enjoy the text by themselves.

The child's level of command of TID is another particularly important issue to be considered. With the present-day schooling system in Turkey, Deaf children are placed in inclusive classrooms where they learn written language alongside their hearing peers. There is no special classroom for them to learn TID (Kargin, 2004). The children can learn TID from their Deaf parents or other Deaf adults and children, or in special schools. Because of this diverse language input, it is difficult to gauge their language proficiency. The team insisted on having a 'typical' representative from the youngest age range targeted to ensure as far as possible that the interpretation was suitable. (For research on reading abilities and linguistic development of Deaf children see: Andrews, 1986, 1987; Bailes, 2001, 2009; Berke, 2013; Erting, 1992; Gaudelet Research Institute, 2011; Goldin-Meadow, 2001; Padden, 1998, 2000; Wilbur, 2000a).

To summarize, even though there can be no definite guidelines on the interpretation of the material in question, it is important to keep in mind the differences between the receivers of the source text and the Deaf children.

Furthermore, a Deaf child (or possibly a group of children) should be involved in the process. The interpreting team should be picked from among experts who have experience with the linguistic abilities of a variety of Deaf children from different families and other settings (e.g. Deaf child of Deaf parents, Deaf child of hearing parents).

\subsection{Dealing with different cultures}

In translating children's books not specifically written for Deaf children the main character is usually a hearing child. The Deaf child may well empathize with the main character, but this character will remain other. S/he does not share the same physiological and other social realities with the Deaf child. On the other hand, experiencing the story of a hearing child may allow Deaf children to better understand the realities of the hearing world which they will have to live in.

A second issue is that children's books aimed at a wide range of children will usually (if not specifically designed otherwise) involve many aspects of the hearing world. A classic example is a child waking to the sound of an alarm clock; in contrast a Deaf child would be wakened by a vibrating clock or light alarm. To take another example, in the Selim series, Selim lives with his sister, parents and grandmother in a house with a single bathroom. Every morning the siblings fight over bathroomtime. In the story, Selim, tired of his sister hogging the bathroom in the mornings, locks himself in the bathroom and does not respond to his sister who is standing in front of the locked bathroom door. She repeatedly calls out his name and demands that he get out of the bathroom. The repetition of Selim's name and his sister making noise in front of the door are rooted in the interactions of hearing people. If Deaf siblings were involved, the one standing outside the door would turn the lights on and off or pass a note under the door. Another example from the Selim series is Selim being woken by his grandmother making noise as the goes to the kitchen to prepare breakfast. He wakes up because she makes noise. He prefers to go back to sleep and pulls the covers over his head to block out the sound. A Deaf child would only wake up if they saw light. In this instance a part was added to the story where 
Selim's grandmother wakes him up, and he pulls the cover over his head to be able to sleep despite the sunlight streaming through his window.

Another example of cultural difference is the use of lyrics and singing in children's books. The Deaf child may not know the lyrics to songs that are widely known by hearing children (for details on Deaf children and music see: Mitani et al, 2007). Such references may not be understood and may have to be deleted. On the other hand, the Deaf child will probably know of the concept of singing and its association with fun (for details of the role of music in Deaf culture see: Darrow, 2006). For example, in the Selim series, when Selim and his sister are singing Selim points out that they are getting the words wrong. In such a case one possibility is to write new signed lyrics for the Deaf child. This was the option chosen by the team. The song and its purpose were retained (e.g., Selim and his sister are having fun singing as a part of enjoying school).

\subsection{Interpreting animal characters}

As mentioned in section 2.2.2, the interpreter must be able to mimic the body movements and facial expression of the animal characters so that it is clear who is referred to. Since this is also common practice in everyday TID (as it is in most sign languages), this will make the interpreting natural and enjoyable.

The sign naming tradition for people also applies to animal characters, it should be mentioned that there are generally no common names for cats (e.g., Smokey), dogs (e.g., Butch), and other animals. The characters were named using the same strategies discussed in section 3.1. The names may also be replaced with descriptive terms such as YELLOW CAT or BLACK DOG. The sounds and noises that animals make (e.g., roaring, barking) may be mimicked with lips and facial expressions familiar to Deaf children.

\subsection{Some linguistic issues}

The interpreting process that involves moving from a written text to a sign language requires many linguistic changes in both micro and macro structures. A comprehensive list of all changes cannot be provided and would not serve a purpose as all decisions made by the team as regards these changes would only be valid for the project in question. Here we will illustrate such changes from the current project to give a general idea of what is involved.

It is essential to present the Deaf child with an interpreted text that is both linguistically correct and that contains natural discourse (not a stilted translationese which would deter their enjoyment of the product) in their L1. Since the receivers are children, it is important for the story to be lively to grab and keep their attention.

It is natural for sentences to be divided and joined when interpreting into TID or any other language. But with sign languages there are the possibilities of simultaneity. In sign language (as opposed to written language) some features can be presented simultaneously. For example, 'the man picked up his suitcase and his umbrella' is presented in a sequence in written language, but the interpreter may present these simultaneously signing (mimicking) the picking up of the suitcase with one hand and the umbrella with the other. Thus, the possibilities of simultaneity in a sign language can replace devices such as coordination and subordination in the spoken language.

Some sentences or sentence fragments also need to be changed to suit the linguistic and storytelling traditions of the Deaf community. For example, repeatedly calling out to a character or repeating their name is not part of Deaf culture. Such repetitions could be deleted (e.g., Selim! Selim come here. I am 
calling you Selim. Do you not hear me? Selim!) and fragments added (e.g., MOTHER CALL SELIM. CALL SELIM MUCH. HE NOT COME. SHE MAD GET START).

Sometimes narrative structures need to be changed to produce a cohesive text in line with Deaf storytelling traditions. For example, spoken languages can mark changes in point of view using strategies such as direct and indirect reported speech. According to Earis \& Cormier (2014) in signed languages, changes in point of view can be marked using role shift, a common device in sign language narrative discourse. The signer mimics a human or animate referent by assuming attributes of the referent. In role shifting, verbs and pronouns that are marked for first person refer to the referent being portrayed not the signer.

It is important for the interpreter to be wary of words and signs that appear to be equivalents since these may be used in different contexts and thus may cause confusion. For example, when Selim is in the bathroom, he says something along the lines of his sister 'occupying the bathroom' every morning. The word 'occupy' (işgal etmek) does exist in TID but will not be used by Deaf children figurativelyonly in the sense of an army occupying a piece of land. Literal translations will cause unnecessary misunderstandings. Also, in some instances there are multiple signs for a single word. For example, the word for fortune telling (e.g., with cards, coffee reading, loves me loves me not) is fal in Turkish. On the other hand, in TID there are separate signs for each type of fortune telling. It is important for the interpreter to pick and choose the word closest to the one the author intended. These are of course issues that interpreters encounter when working not only with sign language but also other language combinations.

TID has a narrower repertoire of tenses when compared to Turkish. So, different tenses will be used to interpret into TID. For example, in the Turkish sentence 'bana söylendiğine göre onu dinlendiriyormuş'(my father tells me this relaxes him) the author uses pluperfect tense that may be explained as relaying reported speech in the past perfect tense in Turkish. In the sentence 'Domatesleri yıkarken, maydanozları doğrarken, günün bütün yorgunluğunu unutuyormuş...' - (While washing tomatoes, cutting up parsley he says he forgets the toils of his day) the author uses simple present tense and synchrony in Turkish. TID does not have tense suffixes and the past tense is expressed with the addition of an adverb of time (see Dikyuva \& Zeshan 2008, p.79). This segment was interpreted in the past tense with an adverb of time (after one day, all day) as FATHER TIRED AFTER ONE DAYALL DAY. HE CUT TOMATOES RELAX. HIS HEAD RELAX.

Finally, TID allows its users to express words and phrases with expressions, gestures and mimics (this is of course an overly simplistic explanation of the use of these in sign languages. For details see: Armstrong, 2003, Wilbur, 2000b). This means that the signing of some expressions present in the original will be redundant if these are presented with other features of the language. For example, 'Selim is very very sad' may be expressed with the signs 'SELIM SAD' accompanied simultaneously by the interpreter assuming a devastated facial expression and the sloping of the shoulders and body to imply the intensity of the feeling.

The use of slang, play-on-words are notoriously difficult to translate since they are often specific to one language (for discussion see: Linder, 2000; Delabastita, 1994, 1996a, 1996b, 1997). In most cases when interpreting from Turkish into TID, it is safe to say, play on words with for example homonymy or synonymy will not be relayed. Expressions like in cin top oynuyordu (there wasn't a soul around) would be rendered as for example LOOK AROUND ME (facial expression denoting watching and movement of head from left to right several times). (Pointing around) PEOPLE NO. EMPTY. Exclamations and interjections would be relayed with the relevant facial expression (for example Oh! -showing surprise- would be relayed with widening of eyes, backward tilt of head and neck and raising of eyebrows). 
Furthermore, the distinction between T-V forms does not exist in TID. V forms are used in Turkish to convey formality indicating varying levels of politeness, courtesy etc. For example, addressing a single individual using the second-person plural forms in the language, instead of the singular denotes formality (for discussion of T-V distinction see Clyne, 2009; Cook, 2014). The V form does not exist in TID but is only used rarely by Deaf adults who learn such address forms as they interact with the hearing culture. These are a further example of the difficulties that must be dealt with in the interpreting process.

\section{Technical concerns and design issues}

In projects such as the one outlined since there is a shift from written to sign language technical concerns and design options are of central importance. Decisions about the medium and its design will also affect the implementation of the project. Thus, there are technical and design related options that must be considered in the type of project described.

The positioning of the interpreter is one of these. In general, a sign language interpreter may either sit or stand. However, for this project the interpreter was asked to stand and so she was able use her body and arms freely. She could use the lower half of her body as well if necessary (e.g., pointing to her leg). Since the illustrations are static, an active narrator who is free to move will make the story more lively and more engaging for Deaf children.

The interpreter can be more of less foregrounded. The interpreter can be constantly present throughout the video with the backdrop of the illustrations changing as the story progresses. This option foregrounds the interpreter. The illustrations become the backdrop against which the story is presented. This may lead to a fragmented style of storytelling in terms of the visuals (illustrations). The illustrations can also appear first with the interpreter placed on top of the illustrations in different positions (centre screen, left bottom etc.). The interpreter appears simultaneously with the relevant illustration (or with a very minimal time lag). She then disappears when the interpreting has finished, and the page is turned (video simulation).

The interpreter may straightforwardly interpret the text. She is then placed on the bottom left or right, the left- or right-hand side of the full screen, or the middle of the screen throughout the video. The interpreter may also interact with the illustration, for example situate her body to imply speaking about certain characters or position herself to sign the dialogues of certain characters. For example, in the ASL Storytelling series available online in "David goes to School" the narrator is pointing to the picture to her right (time- 00.25) to show the character David (ASL Storytelling David Goes to School. (Jul 15, 2020) David Goes to School written by David Shannon. ASL Storytelling by Lisa Cochran. Accessed from: https://youtu.be/zCxTzHQrjgo.)

The positioning of the interpreter on the screen is also a design issue. It is desirable to choose one position for the interpreter that fits with the illustrations. In most cases, however the position will have to change from one page to the next in order not to obscure important information. For example, in the video "If You Give a Pig a Party": ASL Storytelling (2010) available online ("If You Give a Pig a Party" (January 10, 2020) by Laura Numeroff \& Felicia Bond Signed by Justin Jackerson, Accessed from: https://youtu.be/6oisYb6T0AQ) the narrator initially appears at the left side of the screen (time$0: 03)$, then moves farther left when he is narrating about the page displayed on the right of the screen (time- 0:11), to the right when he is narrating about the page displayed on the left side of the screen (time-0:22), and to the middle of the screen when he is narrating a two-page illustration (time-0:42).

Choices also must be made with respect to the presentation of the written text of the book. The book may be presented as a whole (illustrations and text). This will enable the child to become acquainted with the book format. The child will also have the two options of accessing the signed text 
and the written text. The presentation of the written text can support the child's reading skills. On the other hand, presenting the written text will limit the space available to present the interpreter. It may confuse the child, creating the need to read the text and watch the interpreting. Since the child may not be able to follow both s/he may become frustrated. Children able to follow both languages (written Turkish and TID) may end up comparing the two and dwelling on the inevitable linguistic differences, which is not an aim of the project. This option may be particularly good for projects where the language of the original is simple, that is single sentences and where the aim of the project is to promote bilingualism.

A second possibility is to separate the text and the illustrations, presenting the text as subtitles at the bottom of the screen. In this option the interpreter could not be placed at the bottom left or right of the screen since s/he would block the subtitles.

A third option is to remove the text altogether. This allows the child to focus on a single source of input. However, it is only effective with children who have a good command of TID. On the other hand, it emphasizes that the story is created especially for them.

There are also several options for illustrations. Should the writer and illustrator consent, the illustrations can be re-drawn. The illustrator could consider the positioning of the interpreter on each page and re-design (re-draw) the page accordingly to make sure that the interpreter never blocks any part of the illustrations. A second option is to modify the illustrations adding features such as animation, movement. This technique was used in Kinderbücher in Gebärdensprache - "Ich auch!"(2016). It is successful but costly.

A third option is to present the video in book format in the visual. In this case further decisions are required. If the book is to be presented in its original format (which is the least costly option), then there will be single page illustrations, two different illustrations on two separate pages the reader will see together when the child turns the page, and illustrations spanning two pages of the book (see example given above about positioning of narrator- time: 0:42-"If You Give a Pig a Party" (January 10, 2020) by Laura Numeroff \& Felicia Bond Signed by Justin Jackerson, Accessed from: https://youtu.be/6oisYb6T0AQ-)- Whereas the decision to present each individual page separately will be technically easier to implement, there may be slight problems if the illustrator has spilled over from one drawing to the illustration on the next page (e.g. the vine of a bush on one page intertwines with the garden presented on the next illustrated page). These need to be edited so as not to lose the artistry of the illustrations. If there is an illustration spanning two pages (e.g., a 'panoramic' illustration), this would also need to be configured to the screen settings.

The team also needs to consider how to present the pages. One option is to simulate page turning. This option would allow the child to become acquainted with the book format (versus the video, audiovisual product format).

The above given examples are not a comprehensive list of either options or decisions to be made during the process. A technical expert is an essential member of the team since s/he can implement the decisions illustrated above. The technical expert would also record the signed texts, edit the visuals, add effects etc.

\section{Discussion}

To understand the importance of projects such as the one detailed, we need to refer to certain figures to contextualise the need.

The number of persons with disabilities in the national data base (T.C. Aile, Çalışma ve Sosyal Hizmetler Bakanlığı. (2020). Engelli ve Yaşlı İstatistik Bülteni.) 


\begin{tabular}{|l|l|l|}
\hline Disability & Pax & $(\%)$ \\
\hline Visual & 215.076 & 9,53 \\
\hline Hearing & 179.867 & 7,97 \\
\hline Language and Speech & 33.686 & 1,49 \\
\hline Orthopedik & 311.131 & 13,78 \\
\hline Cognitive & 385.313 & 17,07 \\
\hline Psychological & 170.927 & 7,57 \\
\hline Chronic illness & 917.259 & 40,63 \\
\hline Other & 44.248 & 1,96 \\
\hline
\end{tabular}

In consideration of the statistics provided above (which do not give a wholly comprehensive picture as these statistics only cite people registered in the system) it is clear we are referring to a large population in need of access to all forms of culture and literature. As was discussed initially this need is especially relevant for integration into the larger society at a young age.

According to preliminary research done for the project a simple search on the internet reveals that there are various types of video books available for children in many European languages. For example, in many sign languages we can talk of a variety of online sites that provide hundreds of sign language video books:

\begin{tabular}{|l|l|}
\hline Site & Language \\
\hline San Francisco Public Library & American Sign Language (ASL) \\
\hline $\begin{array}{l}\text { American Society for Deaf } \\
\text { Children (ASL Stories Directory) }\end{array}$ & ASL \\
\hline $\begin{array}{l}\text { The Indianapolis Public Library } \\
\text { (Video Read Alouds for Kids in } \\
\text { American Sign Language (ASL) }\end{array}$ & ASL \\
\hline Deaf Mall Books and Videos & ASL \\
\hline VideoLibros en Senas & Argentine Sign Language \\
\hline Donnajonapoli.com/videobooks & $\begin{array}{l}\text { ASL \&sign languages of Austria, } \\
\text { Belgium, Brazil, Bulgaria, China, } \\
\text { Fiji, France, Germany, Grenada, } \\
\text { India, Iran, Ireland, Israel, Italy, } \\
\text { Japan, Korea, Nepal, Nigeria, } \\
\text { Norway, Poland, Russia, Saudi } \\
\text { Arabia, South Africa, Sweden, } \\
\text { Switzerland, Taiwan, Trinidad \& } \\
\text { Tobago }\end{array}$ \\
\hline
\end{tabular}

Furthermore, there is research on 'good practices' in signed video books for children in many languages but endeavours in Turkey remain extremely limited. Some examples are as presented below:

\begin{tabular}{|l|l|}
\hline Institution & Product- video book \\
\hline $\begin{array}{l}\text { Students of İstanbul Culture University \& Children’s } \\
\text { Education Association }\end{array}$ & Moni ve Bobo \\
\hline TÖMER coordinators of Signed Languages & Merhaba, Benim Adım Koronavirüs \\
\hline Sabancı Foundation & $\begin{array}{l}\text { Türk İşaret Dili Kullanan Sağır Çocuklar İçin İkidilli } \\
\text { Okuma Gelişimi Uygulamaları }\end{array}$ \\
\hline
\end{tabular}


Much work must be done in order to provide children with L1Turkish sign language integration with Turkish children's books. It is important however to ensure that quality is a major concern in such projects. As the article outlines there are several tiers of such initiatives where quality markers are sought.

The first quality marker is choosing the correct team of experts to work with. As detailed in section 2.1 the profiles of the team members and the workflow design are of central importance. Otherwise as discussed in the stated section the quality of the product will not serve its purpose.

A second quality marker hinges on the interpreting process itself, as is detailed in section 3. A group of translation scholars are as essential to the quality of the product as are the interpreting team as interpreting choices must be undertaken wisely and based on research in the field.

A third quality marker will be about the technical issues discussed under section 4. Once again research is essential at this stage as well as an experienced team of technical experts who work in cooperation with the rest of the group.

Such an initiative on such important issues (education, societal integration etc.) dealing with a disadvantaged group of receivers (Deaf and $\mathrm{HoH}$ children) deserves to be well thought out from the start and requires extensive planning and coordination from a large team of professionals each contributing in terms of their field of expertise. Whereas social projects aimed at Deaf and $\mathrm{HoH}$ children and access to literature are always appreciated, it is important to note that social projects are usually one-time endeavours and furthermore by virtue of their structure hinge more on the aim and not academically grounded research integrated into practice.

It is extremely heartening to see that such efforts are on the agenda in Turkey but as can be observed from the paper much work needs to be undertaken for better quality in the Turkish setting and furthermore such efforts need to be studied to provide more comprehensive guidelines that each contributor can build on.

Another perspective that needs to be integrated into such projects is research on reception studies. Whereas in the project outlined a sample group was selected from among end-users to verify accessibility an essential next step would be research through eye-tracking and other cognitive translation studies research tools to ensure quality and to pinpoint end-users' desires and needs.

\section{Conclusions}

The project outlined in the article was the first of its kind in Turkey. The project team has received positive responses from the parents of Deaf children. SEBEDER, the first NGO in Turkey that works on accessibility to audio-visual products for the visually impaired, D/deaf and Hard of Hearing through sign language interpreting, subtitling and audio description would like to enlarge its repertoire of such video-books with the contributions of authors and illustrators.

This project achieved several important goals. Initially it raised awareness about the possibility and use of such projects in Turkey. Secondly, a draft manual was compiled to help later projects. In the long run (when there is a variety of input from different sources) this could be written up as a

guideline for further projects in Turkish-TID. Furthermore, this project brought together a multidisciplinary team of experts who were able to learn from each other. For example, the sign language team learned about the possibilities of translation; the academics experienced working with Deaf adults and children.

Most importantly the video-books are currently being viewed by Deaf children bringing authors, their works and the children closer to one another. This is hopefully helping to instil enjoyment of literature, reading and children's books in Deaf children. 
One of the most important aspects of ensuring accessibility is to do so while respecting the rights of the people for whom the interpreting is done. Facilitating the Deaf child's ability to access literature that would be read aloud to other children in the video book format with sign language interpreting shows respect for the child's identity and culture. It also allows the child to discover a world of literature that is enjoyable and rich which would otherwise be inaccessible to them. Such endeavours lie at the heart of the issue of accessibility for many groups and deserve no less attention then translating children's books across a variety of languages. Projects such as the one presented here will hopefully not only allow Deaf children to access the world of literature but also to develop an interest in it.

\section{References}

Andrews, J.\& Mason, J. (1986). Childhood Deafness and the Acquisition of Print Concepts. In D.B. Yaden \& S. Templeton (Eds) Metalinguistic awareness and beginning literacy, 277-290. Portsmouth, NH: Heinemann.

Andrews, J. F. \& Taylor, N. E. (1987). "From sign to print: A case study of picture book "reading" between mother and child." Sign Language Studies, 56, 261-274.

Arfé, B. \& Cristina Rossi, C. \& Sicoli, S. (2015). The Contribution of Verbal Working Memory to Deaf Children's Oral and Written Production. The Journal of Deaf Studies and Deaf Education, 20 (3), 203-214.

Armstrong, D. (2003). Language, Cognition, and the Brain: Insights from Sign Language Research (review). Sign Language Studies, 4, 83-90. 10.1353/sls.2003.0020.

Bailes, C. (2001). Integrative ASL-English language arts: Bridging paths to literacy. Sign Language Studies, 1, 147-174.

Bailes, C. Erting, C., Erting, L., Thumann-Prezioso, C. (2009). Language and literacy acquisition through parental mediation in American Sign Language. Sign Language Studies, 9, 417-456.

Baker, A, van den Bogaerde, B., Pfau, R. \& Schermer, T. (Eds). (2016). The Linguistics of Sign Languages: An Introduction. Amsterdam: John Benjamins.

Berke, M. (2013). Reading Books with Young Deaf Children: Strategies for Mediating Between American Sign Language and English. The Journal of Deaf Studies and Deaf Education, 18(3), 299-311.

Calderon, R. (2000). Parental Involvement in Deaf Children's Education Programs as a Predictor of Child's Language, Early Reading, and Social-Emotional Development. The Journal of Deaf Studies and Deaf Education, 5(2), 140-155.

Calderon, R. \& Greenberg, M.T. (2012). "Social and Emotional Development of Deaf Children: Family, School, and Program Effects." In M. Marschark \& P. E. Spencer (Eds.) The Oxford Handbook of Deaf Studies, Language, and Education: Second Edition, (pp.1-21). Oxford: Oxford University Press.

Clyne, M. (2009). Address in intercultural communication across languages. Intercultural Pragmatics. 9(3), 395-409.

Convention on the Rights of Persons with Disabilities, (CPRD). (2006). Accessed March 2, 2020, from: https://www.un.org/development/desa/disabilities/convention-on-the-rights-ofpersons-withdisabilities.html 
Cook, M. (2014). Beyond T and V - Theoretical reflections on the analysis of forms of address. American Journal of Linguistics, 3(1), 17-26.

Darrow, A. A. (2006). The Role of Music in Deaf Culture: Deaf Students' Perception of Emotion in Music. Journal of Music Therapy, 43(1), 2-15.

Darwish, I.\& Sayaheen, B. (2019). Manipulating Titles in Translation. Journal of Educational and Social Research, 9(3), 239-245.

Delabastita, D. (1994). Focus on the pun: wordplay as a special problem in translation studies. Target: International Journal on Translation Studies, 6(2), 223-243.

Delabastita, D. (1996a). Introduction. The translator: Studies in intercultural communication special issue: Wordplay and translation, 2(2), 127-139.

Delabastita, D. (ed.). (1996b). Wordplay and translation. Manchester: St. Jerome Publishing.

Delabastita, D. (ed.). (1997). Traductio: Essays on punning and translation. Manchester: St. Jerome Publishing.

Department of Education. (2012). Research evidence on reading for pleasure: Education standards research team. Accessed March 2, 2020 from: https://assets.publishing.service.gov.uk/government/uploads/system/uploads/attac hment_ data/file/284286/reading_for_pleasure.pdf.

Dikyuva, H. \& Zeshan, U. (2008). Türk İşaret Dili. Nijmengen: Ishara Press.

Earis, H. \& Cormier, K. (2014). Point of view in British Sign Language and spoken English narrative discourse: The example of 'The Tortoise and the Hare'. Language and Cognition, 5, 313-343. 10.1515/langcog-2013-0021.

Ellis, K. \& Kent, M. (2011). Disability and New Media. New York and London: Routledge.

Erting, C. (1992). Deafness \& literacy: Why Can't Sam Read? Sign Language Studies, 75, 98-112.

Gallaudet Research Institute. (2011). Regional and National Summary Report of Data from the 200910 Annual Survey of Deaf and Hard of Hearing Children and Youth. Washington, DC: GRI, Gallaudet University.

Gambier, Y. (2006). "Multimodality and Audiovisual Translation." In M. Carroll, H. GerzymischArbogast \&S. Nauert (Eds) Audiovisual Translation Scenarios: Proceedings of the Marie Curie Euroconferences MuTra: Audiovisual Translation Scenarios, Copenhagen 1-5 May 2006, http://www.euroconferences.info/proceedings/2006_Proceedings/2006_proceedings.html.

Goldin-Meadow, S. \& Mayberry, R. (2001). How Do Profoundly Deaf Children Learn to Read? Learning Disabilities Research \& Practice, 16, 222-229.

Hallford, D. \& E. Zaghini. (2005). Outside In: Children's Books in Translation. London: Milet Publishing Ltd.

Heilbron, J. (1999). Towards a Sociology of Translation: Book Translations as a Cultural World System. European Journal of Social Theory, 2(4), 429-444.

Hoffmeister, R. \& Chamberlain, C. \& Morford J. \& Mayberry R. (2000). A Piece of the Puzzle: ASL and Reading Comprehension in Deaf Children, Language Acquisition by Eye. In B. Schick, M. Marschark, P. E. Spencer Advances in the Sign Language Development of Deaf Children, (pp.143163). Oxford: Oxford University Press. 
Jackson, A. (2001). Language Facility and Theory of Mind Development in Deaf Children. The Journal of Deaf Studies and Deaf Education, 6(3), 161-176.

Jovanovic, M. (1990). On translating titles. Babel, 36(4), 213-222.

Kargın, T. (2004). Kaynaştırma: Tanımı, Gelişimi ve İlkeleri. Ankara Üniversitesi Eğitim Bilimleri Fakültesi Özel Eğitim Dergisi, 5(2), 1-13.

Kinderbücher in Gebärdensprache - "Ich auch!". (2016). Accessed September, 4, 2019. https://www.youtube.com/watch?v=YlKPIRpTyqg.

Lathey, G. (ed.). (2006). The Translation of Children's Literature: A Reader. Cleavedon: Mutltilingual Matters.

Lathey, G. (2010). The Role of Translators in Children's Literature: Invisible Storytellers. London and New York: Routledge.

Lazar, J. \& M. A. Stein. (eds.). (2017). Disability, Human Rights, and Information Technology. Pennsylvania: University of Pennsylvania Press.

Linder, D. (2000). Translating slang in detective fiction. Perspectives: Studies in Translatology, 8(4), 275-287. DOI: 10.1080/0907676X.2000.9961396

Mdallel, S. (2003). Translating Children's Literature in the Arab World: The State of the Art. Meta, 48(1-2), 298-306.

Media for All. 2019. M4A8- 8th Media for All International Conference. Accessed on March 2, 2020 from: https://www.tolk.su.se/english/media-for-all-8.

Messier, J. \& Wood, C. (2015). Facilitating Vocabulary Acquisition of Children With Cochlear Implants Using Electronic Storybooks. The Journal of Deaf Studies and Deaf Education, 20(4), $356-373$.

Mindess, A. (1990). What Name Signs Can Tell Us About Deaf Culture. Sign Language Studies, 66 (Spring 1990), 1-23.

Mitani, C. \& Nakata, T. \& Trehub, S. \& Kanda, Y. \& Kumagami, H. \& Takasaki, K. \& Miyamoto, I. \& Takahashi, H. (2007). Music Recognition, Music Listening, and Word Recognition by Deaf Children with Cochlear Implants. Ear and hearing, 28, 29-33.

Mudgett-DeCaro, P. A. 2011. A Unique “Coda space': Between Deaf and Hearing Worlds. The Journal of Deaf Studies and Deaf Education, 16(4), 556. https://doi.org/10.1093/deafed/enr006

Neydim, N. (2011a). Selim'in Maceraları 1: Salata Yapan Çocuk. İstanbul: Şimşek Yayınları.

Neydim, N. (2011b). Selim'in Maceraları 2: Papatya Dostum Benim. İstanbul: Şimşek Yayınları

Neydim, N. (2011c). Selim ’in Maceraları 3: Aynı Dili Konuşmak. İstanbul: Şimşek Yayınları.

O'Connel, E. (2006). Translating for Children.” In G. Lathey (Ed.) The Translation of Children's Literature: A Reader, (pp.14-25). Toronto: Multilingual Matters.

Oittinen, R. (2000). Translating for Children. New York London: Garland Publishing Inc.

Paales, Liina. (2011). Name Signs for Hearing People. Folklore (Estonia), 47, 43-76.

Padden, C. \& Ramsey, C. (1998). Reading Ability in Signing Deaf Children. Topics in Language Disorders, 18, 30-46. 
Padden, C. \& Ramsey, C. (2000). American Sign Language and Reading Ability in Deaf Children.” In C. Chamberlain \& J.P. Morford J.P. \& R.I Mayberry (Eds.) Language acquisition by eye (pp 165189). Mahwah, NJ: Lawrence Erlbaum Associates.

Pinsent, P. (ed). (2006). No Child is an Island: the Case for Children's Literature in Translation. UK: Pied Piper Publishing.

Puurtinen, T. (1995). Linguistic Acceptability in Translated Literature. Joensuu: University of Joensuu Press.

Quer, J. (2018). On categorizing types of role shift in Sign languages. Theoretical Linguistics, 44(3-4), 277-282. doi: https://doi.org/10.1515/tl-2018-0020

Rhys-Jones, S. \& Ellis, H. (2000). Theory of Mind: Deaf and Hearing Children's Comprehension of Picture Stories and Judgments of Social Situations. The Journal of Deaf Studies and Deaf Education, 5(3), 248-265.

Rosenheim, E. W. (1967). Children's Reading and Adults' Values. The Library Quarterly: Information, Community, Policy, 37(1), 3-14.

SEBEDER, (2019). Ana Sayfa. Accessed September, 4, 2019. http://sebeder.org/index.php.

Shavit, Z. (1996). The Poetics of Children's Literature. Athens: University of Georgia Press.

Swanwick, R. \& Watson, L. (2007). Parents Sharing Books with Young Deaf Children in Spoken English and in BSL: The Common and Diverse Features of Different Language Settings. The Journal of Deaf Studies and Deaf Education, 12(3), 385-405.

Taylor, C. (2013). Multimodality and Audiovisual Translation. In Y.Gambier, \& L. van Doorslaer Handbook of Translation Studies, 4, 98-104, Amsterdam: John Benjamins.

Taylor, C. (2016). The Multimodal Approach in Audiovisual Translation. Target, 28(2), 222-236.

T.C. Aile, Çalışma ve Sosyal Hizmetler Bakanlığı. (2020). Engelli ve Yaşlı İstatistik Bülteni. https://www.ailevecalisma.gov.tr/media/42250/istatistik-bulteni-2020-mart.pdf

Texas Deaf/Hard of Hearing Services. (2018). Children's Stories in Sign Language, Livebinder project. Accesssed on March 2, 2020 from http://www.livebinders.com/play/play?id=1662407

TIED, (2019). Hakkımızda. Accessed on September 4, 2019 from https://tied.org.tr/.

TÜIK \& ASPB. (2010). Özürlülerin sorun ve beklentileri araştırması. Ankara: TÜIK ve ASPB. Accessed on September, 4, 2019 from https://kutuphane.tuik.gov.tr/pdf/0014899.pdf.

Understanding Quality in Media Accessibility (UMAQ). (2018). The UMAQ Project, the UMAQ Conference. Accesssed on March 2, 2020 from http://pagines.uab.cat/umaq/umaq-conference

Van Collie, J. \& P. Verschueren (eds.). (2006). Children's Literature in Translation. Manchester: St Jerome.

Wauters, L. \& Dirks, E. (2017). Interactive Reading with Young Deaf and Hard-of Hearing Children in eBooks Versus Print Books. The Journal of Deaf Studies and Deaf Education, 22(2), 243-252.

Wilbur, R. (2000a). The use of ASL to support the development of English and literacy. Journal of Deaf Studies and Deaf Education, 5, 81-104.

Wilbur, R. (2000b). Phonological and prosodic layering of non-manuals in American Sign Language. In K.Emmorey K, H. Lane (Eds). The signs of language revisited. (pp.215-247). Mahwah, NJ: Lawrence Erlbaum Associates. 
Yamazaki, A. (2002). Why Change Names? On the Translation of Children's Books. Children's Literature in Education, 33(1), 53-62.

\section{AUTHOR BIODATA}

Assoc. Prof. Dr. Sirin Okyayuz is a trainer and researcher at Hacettepe University Department of Translation and Interpreting in Ankara- Turkey. Her research fields are literary translation, audio-visual translation, translation of popular culture products and translator training. Her articles spanning subjects such as literary translation, AVT, translation of politics, and accessibility have been published in international peer reviewed journals and she has published several books and contributed to compilations detailing AVT training and practices in Turkey. She has translated bestselling novels in the popular genre, books on politics and philosophy, comics, adapted children's books, drama for the Turkish State Theatre and also works as an AV translator. 